\title{
Racial Differences in Cervical Cancer Survival in the Detroit Metropolitan Area
}

\author{
Sujana Movva, MD'1, Anne-Michelle Noone, MS$^{2}$, Mousumi Banerjee, PhD², Divya A. Patel, \\ $\mathrm{PhD}^{3}$, Kendra Schwartz, MD, MSPH ${ }^{4,5}$, Cecilia L. Yee, MS $^{5}$, and Michael S. Simon, MD, \\ $\mathrm{MPH}^{5,6}$ \\ ${ }^{1}$ Department of Internal Medicine, Mclaren Regional Medical Center, Michigan State University, \\ Flint, Michigan \\ ${ }^{2}$ Department of Biostatistics, School of Public Health, University of Michigan, Ann Arbor, Michigan \\ ${ }^{3}$ Department of Obstetrics and Gynecology, University of Michigan, Ann Arbor, Michigan \\ ${ }^{4}$ Department of Family Medicine and Public Health Sciences, Wayne State University, Detroit, \\ Michigan \\ ${ }^{5}$ Population Studies and Prevention Program, Karmanos Cancer Institute at Wayne State \\ University, Detroit, Michigan \\ ${ }^{6}$ Division of Hematology and Oncology, Karmanos Cancer Institute at Wayne State University, \\ Detroit, Michigan
}

\section{Abstract}

BACKGROUND-African-American (AA) women have lower survival rates from cervical cancer compared with white women. The objective of this study was to examine the influence of socioeconomic status (SES) and other variables on racial disparities in overall survival among women with invasive cervical cancer.

METHODS-One thousand thirty-six women (705 white women and 331 AA women) who were diagnosed with primary invasive cancer of the cervix between 1988 and 1992 were identified through the Metropolitan Detroit Cancer Surveillance System (MDCSS), a registry in the Surveillance, Epidemiology, and End Results (SEER) database. Pathology, treatment, and survival data were obtained through SEER. SES was categorized by using occupation, poverty, and educational status at the census tract level. Cox proportional hazards models were used to compare overall survival between AA women and white women adjusting for sociodemographics, clinical presentation, and treatment.

RESULTS-AA women were more likely to present at an older age $(P<.001)$, with later stage disease $(P<.001)$, and with squamous histology $(P=.01)$, and they were more likely to reside in a census tract categorized as Working Poor (WP) $(P<.001)$. After multivariate adjustment, race no longer had a significant impact on survival. Women who resided in a WP census tract had a higher risk of death than women from a Professional census tract $(P=.05)$. There was a significant interaction between disease stage and time with the effect of stage on survival attenuated after 6 years. 
CONCLUSIONS-In this study, factors that affected access to medical care appeared to have a more important influence than race on the long-term survival of women with invasive cervical cancer.

\section{Keywords}

cervical cancer; survival; race; socioeconomic status; Surveillance; Epidemiology; End Results

Cancer of the cervix is the third most common malignancy of the female reproductive system. ${ }^{1}$ The American Cancer Society estimates that 11,150 women will be diagnosed with and 3670 women will die from cervical cancer in $2007 .^{2}$ Data from the Surveillance, Epidemiology, and End Results (SEER) Program have indicated that, whereas the 5-five year relative survival rates for cervical cancer have increased from 1975 to 2002 for all women (from $69.1 \%$ to $73.5 \%$ ), survival rates remain lower for African-American (AA) women compared with white women. ${ }^{3}$ During the period from 1996 to 2002, the relative survival rates were $75 \%$ and $67 \%$ for white women and AA women, respectively. ${ }^{1}$

Racial differences in cervical cancer have been attributed to several factors, including stage at presentation, ${ }^{4-13}$ treatment differences, ${ }^{4,5,8,10,14,15}$ comorbid conditions, ${ }^{14}$ and SES. $6,7,14,16-23$ Unlike information on stage and treatment, however, databases used by public health researchers generally do not include information on individual SES. SES has been described in the cervical cancer literature using various combinations of measures, including poverty level, occupation, educational level, and insurance status. In addition, SES was defined in several studies using the United States Census at the neighborhood (census tract level) or zip code level as a proxy for individual SES.7,14,16,18,20-22 In this regard, Krieger et al. designed the Public Health Disparities Geocoding Project to determine which specific measures of socioeconomic position (education, income, occupation, poverty level) and which geographic level would be most useful for health surveillance and research. ${ }^{24-26}$ In their study on mortality rates and cancer incidence using SEER data, they observed that data based on census tract (average population, 4000) or on census block group (average population, 1000) performed similarly for all outcomes, including external validity, robustness, completeness, and user friendliness. However, the use of data at the United States Postal Service zip code level (average population 30,000) failed in some tests of external validity. ${ }^{24}$

In the current study, we used data from the Metropolitan Detroit Cancer Surveillance System (MDCSS) to determine whether SES had an effect on the observed difference in survival among AA women and white women with cervical cancer. On the basis of methods reported by Krieger et al., ${ }^{27}$ using census tract level data, we defined an SES variable by using information on education, occupation, and poverty as a proxy for individual SES status. This model offers a more inclusive method of defining SES than has been used in other studies that investigated the effect of SES on the survival of women with cervical cancer. $6,7,14,16-23$

\section{MATERIALS AND METHODS}

\section{Study Population}

The study population consisted of women diagnosed with a first primary invasive cancer of the cervix uteri (International Classification of Diseases for Oncology codes C53.0-53.1 and 53.8-53.9). ${ }^{28}$ Women were identified from 1988 to 1992 from the MDCSS, which allowed for a 10-year follow-up through 2002. The SEER Program of the National Cancer Institute reports cancer incidence and survival data on approximately $26 \%$ of the United States population. It was initiated in 1973, with Detroit as 1 of 7 founding members, and now 
consists of 17 registries throughout the United States. ${ }^{29}$ From January 1, 1988 to December 31,1992 , there were 1073 incident cases of female invasive cervical cancer diagnosed in the Detroit metropolitan area: Seven hundred twenty-seven cases (62\%) were classified in the SEER registry as white, and 346 cases $(29.5 \%)$ were classified as AA. Racial designations of other $(\mathrm{n}=13)$, including American Indian, Chinese, Filipino, Korean, Asian Indian, and Laotian, or unknown $(n=17)$, were not included because of the lack of sufficient numbers. In total, 20 women $(2 \%)$ were excluded from the analysis, because they had tumors with nonspecific histology (neoplasm malignant; tumor cells malignant; or carcinoma undifferentiated, not otherwise specified [NOS]). Another 17 women (1.7\%) were excluded if they had a rare histology (carcinoma, anaplastic, NOS; basal cell carcinoma, NOS; neuroendocrine carcinoma; leiomyosarcoma; mullerian mixed tumor; carcinosarcoma; and mesonephroma, malignant). After these exclusions, the final sample size was 1036 women.

\section{Definition of Variables}

Tumor characteristics-Tumor stage was defined according to the International Federation of Gynecology and Obstetrics (FIGO) staging system as stage I, IIA, IIB, III, IV, or unknown. Women with stage IIB cervical cancer are considered to have locally advanced disease and, unlike women with stage IIA disease, are treated with primary chemotherapy and radiation..$^{30}$ Tumor grade was classified as well differentiated, moderately differentiated, poorly differentiated, undifferentiated, or unknown. Lymph node involvement was classified as negative, positive, or unknown. Histology was categorized as squamous cell carcinoma (SCC), adenocarcinoma, or adenosquamous carcinoma. Tumor size was divided into 4 categories: $\leq 7 \mathrm{~mm}$, from $8 \mathrm{~mm}$ to $4 \mathrm{~cm},>4 \mathrm{~cm}$, or unknown.

Demographic characteristics-Marital status at diagnosis was defined as married, unknown, or other (single, separated, divorced, or widowed). Race was classified as AA or white. Age at diagnosis was categorized as $<50$ years or $\geq 50$ years.

Treatment-Surgery and radiation therapy were categorized into a variable that was labeled "first course of cancer-directed treatment." Surgery was categorized as no cancerdirected surgery, local surgery only, simple hysterectomy, radical hysterectomy, or unknown. Local surgery included local surgical excision, excisional biopsy, trachelectomy, amputation of cervix or cervical stump, laser surgery with pathology specimen, or conization. Surgical therapy for preinvasive disease, fertility preservation (cryosurgery, laser surgery, and dilation and curettage), staging evaluation for debulking (pelvic exenteration, surgery of regional and/or distant sites only), and information on surgery that was nonspecific (hysterectomy, NOS or surgery, NOS) was excluded. The data on surgery were categorized further as either no surgery or surgery of any type. Radiation therapy was classified as none or refused, external beam radiation therapy alone, radioactive implants or isotopes with or without external beam radiation therapy, or radiation, NOS or planned radiotherapy. Only 2 women refused radiation therapy and were included with the patients who did not receive any radiation. Like the surgery variable, radiation therapy was categorized further into either no radiation therapy received or radiation therapy of any type. We used information on surgery and radiation therapy to create a first course of cancerdirected treatment variable that consisted of the following 5 categories: neither surgery nor radiation, surgery only, radiation therapy only, surgery and radiation therapy, and unknown. Chemotherapy use was classified as chemotherapy that was either administered or planned, either not administered or refused, or unknown.

SES-A census tract number was obtained from the MDCSS for each woman in the study based on her address at the time of diagnosis. The 1990 United States Census of Population and Housing Summary Tape File 3A was used to obtain socioeconomic data for census 
tract. ${ }^{31}$ The variables that were used to create SES categories included occupation, poverty status, and educational attainment. Occupation was included because it could serve as a proxy for insurance status, in that most health insurance is obtained through an employer. The 1990 United States Census defined 13 occupational categories; 5 for 'Professional' occupations and 8 for 'Working Class' occupations. We defined SES variables corresponding to census tracts based on the definitions published by Krieger et al. for census block groups. ${ }^{27}$ 'Working Class' block groups were defined as those in which $\ 66.67 \%$ of the population in that census block reported a 'working class' occupation, such as a laborer. 'Professional' groups were those in which $\mathbf{3 3} 3.33 \%$ of employed individuals were in executive or supervisory roles. 'Poor' groups were those in which $\geq 20 \%$ of the population lived below the poverty level, which was $\$ 12,674$ for a family of 4 in 1990 . 'Educated' groups were those in which $\geq 75 \%$ of individuals aged $\geq 25$ years had completed at least a high school education.

Women were assigned to 1 of 8 SES groups, including 1) Working, Poor, Undereducated;2) Working, Poor, Educated; 3) Working, Nonpoor, Undereducated; 4) Working, Nonpoor, Educated; 5) Professional, Poor, Undereducated; 6) Professional, Poor, Educated; 7) Professional, Nonpoor, Undereducated; and 8) Professional, Nonpoor, Educated. Because there were insufficient numbers for a meaningful analysis in some of the SES groups, the groups were collapsed into 4 mutually exclusive categories as follows: 1) Working, Poor (WP); 2) Working, Nonpoor, Undereducated (WNP-UE); 3) Working, Nonpoor, Educated (WNP-E); and 4) Professional (P).

\section{Statistical Analysis}

Chi-square tests were used to compare the demographic characteristics, clinical characteristics, and treatment modalities in AA women and white women. $P$ values $<.05$ were considered statistically significant. The primary endpoint was overall survival, which was defined as the time from diagnosis to death from any cause. Univariate (unadjusted) analysis of overall survival was performed using Kaplan-Meier estimates and the log-rank test. Cox proportional hazards regression was used to assess the effect of race on overall survival after adjusting for age at diagnosis (aged $<50$ years, aged $\geq 50$ years), marital status (married, other), SES (WP, WNP-UE, WNP-E, P), stage (I, II, III, IV), chemotherapy (none/ refused, chemotherapy/planned), first-course treatment (neither surgery or radiation, surgery only, radiation only, both surgery and radiation), and histology (adenocarcinoma, squamous, adenosquamous). Tumor grade, size, and lymph node status were not included in the multivariable model because of a lack of statistical significance in the univariate analysis and the large proportion of women with missing information. Tumor size information was accounted for in the FIGO staging classification.

\section{RESULTS}

There were 705 white women and 331 AA women who were included in the study. The mean age at diagnosis was 51.1 years (standard deviation [SD], 17 years), and the mean age was 52.8 years (SD, 16.7 years) for AA women and 50.4 years (SD, 17.1 years) for white women. The median follow-up was 185 months. Demographic characteristics, clinical characteristics and treatment modalities of the study population stratified by race are shown in Table 1 . There were statistically significant differences in all of the characteristics examined except for tumor grade and lymph node status. AA women were more likely to be older at diagnosis ( $54.1 \%$ diagnosed at age $\geq 50$ years vs $46.5 \%$ of white women; $P=.02$ ) and were less likely to be married, (26.6\% vs $49.9 \%$ of white women; $P<.001)$. With regard to SES, AA women were more likely to reside in a census tract categorized as WP (73.1\% vs $15.2 \%)$, whereas white women were more likely to reside in a census tract designated as $\mathrm{P}(33 \%$ vs $13.9 \% ; P<.001)$. AA women also were less likely to present at diagnosis with 
earlier stage disease (48.9\% presented with stage I disease vs $59.6 \%$ of white women; $P<$. $001)$ and were more likely to have large tumors at the time of diagnosis (13.9\% had tumors that measured $>4 \mathrm{~cm}$ compared with $6 \%$ of white women; $P=.003$ ). AA women were more likely to have tumors that were of SCC histology $(87.9 \%$ vs $80.6 \% ; P=.01)$. With regard to treatment, AA women were more likely to have received or planned to receive chemotherapy $(26.3 \%$ vs $15.9 \% ; P<.001)$. Treatment with surgery or radiation also differed between the races $(P<.001)$. White women were more likely to undergo surgery only ( $40.1 \%$ vs $27.6 \%$ ), whereas AA women were more likely to receive radiation only ( $39.4 \%$ vs $30.8 \%)$. Slightly more AA women had neither surgery nor radiation (10.9\% vs $8.5 \%)$.

\section{Survival Analysis}

The median survival of women who were diagnosed with invasive cervical cancer in the Detroit Metropolitan area between 1988 and 1992 was 127 months. The unadjusted analyses (data not shown) demonstrated that AA women had a significantly increased risk of death (hazard ratio [HR], 1.49; 95\% confidence interval [CI], 1.26-1.76) compared with white women. However, when the multivariable model (Table 2) was adjusted simultaneously for age, marital status, SES, histology, stage, and treatment, race no longer had a significant impact on survival (HR, 1.12; 95\% CI, 0.89-1.42). Older women as expected, had an increased risk of death compared with younger women (HR, 2.28; 95\% CI, 1.84-2.83). Being married appeared to have a modest negative influence on survival (HR, 1.23; 95\% CI, 1.01-1.50). Women from the WP census tract had a modestly higher, but not statistically significant, greater risk of death compared with women from the P census tract (HR, 1.30; 95\% CI, 1.00-1.69), and there were no significant differences observed for any of the other census tract groupings (WNP-UE or WNP-E) compared with the P group. Nonsquamous histology (adenocarcinoma or adenosquamous carcinoma) was a significant predictor of worse outcome (adenocarcinoma: HR, 1.89; 95\% CI, 1.41-2.54; adenosquamous carcinoma: HR, 2.34; 95\% CI, 1.62-3.37). Women who either underwent surgery alone, or received radiation therapy alone, or both underwent surgery and received radiotherapy were more likely to have better survival than women who did not undergo any surgery or receive any radiation, and whether or not women received chemotherapy had no significant impact on survival. The effect of disease stage on survival appeared to decay over time when women who had stage II, III, or IV disease were compared with women who had stage I disease. After 6 years, the effect of disease stage on overall survival was no longer statistically significant (data not shown).

\section{DISCUSSION}

Our univariate analysis demonstrated racial differences in survival, with AA women experiencing worse overall survival compared with white women; however, after simultaneously adjusting for multiple potential confounders, including a proxy measure for SES, race no longer had a significant impact on cervical cancer survival. Several previous studies have evaluated race specifically as a predictor of survival for women with cervical cancer. $4,5,7,8,32-38$ Four of 10 studies demonstrated that AA women had worse survival compared with white women despite adjustment for several potential confounder variables, $5,8,32,36$ whereas 6 of 10 studies showed no racial differences in survival after multivariate adjustment. ${ }^{4,33-35,37,38}$ Thoms et al. ${ }^{34}$ reported no survival differences between AA women and white women after adjustment for stage, age and histology. However in their study, 127 women (80\%) were AA, and the small number of white women may have limited the power of the study to evaluate survival differences by race. Grigsby et al. ${ }^{33}$ evaluated 922 women (207 AA women and 715 white women) at the Mallinckrodt Institute of Radiology with either stage II or stage III disease who received radiation therapy and observed no racial difference in cancer-specific survival. However, the 5-year overall 
survival rate for patients who were diagnosed with stage II disease was significantly less for AA women compared with white women ( $51 \%$ vs $60 \%$, respectively; $P=.02)$. This difference in survival was attributed to other noncancer-related factors. ${ }^{33}$

In our study, factors that were associated with poor survival included advanced stage at presentation, lack of appropriate surgery, being married, non-squamous histology, and increasing age. Several reports have demonstrated that AA women have worse survival secondary to presenting at a later stage of disease. ${ }^{4-13}$ According to our data, white women were more likely to present with stage I disease than AA women. Eggleston et al. ${ }^{7}$ studied 7237 women with cervical cancer in the Texas Cancer Registry from 1995 to 2001. Disease stage in that study was categorized as early stage (IA1, IA2, or IB) and late stage (II, III, IV). Consistent with our results, AA women were more likely to be diagnosed with latestage disease (47.3\%) than non-Hispanic white women (37.1\%). A cervical cancer-specific survival analysis demonstrated that women who were diagnosed at a later stage were 6.2 times more likely to die within 80 months than women who were diagnosed at an early stage and that AA women were 1.3 times more likely to die than white women.

Treatment disparities between AA women and white women also have been evaluated in several studies. $4,5,8,10,14,15$ In our study, a slightly greater percentage of AA women compared with white women did not receive either surgery or radiation. Our population of AA women was older than the white population. Consistent with our results, many studies have demonstrated that increasing age is associated with worsening survival among women with cervical cancer. $8,16,17,20,21,38-40$ Older women may use screening less often and may present at a later stage; thus, they may have lower survival rates. Other explanations include the possibility that older patients are more likely to refuse treatment or to have comorbid conditions that preclude standard cancer treatment. ${ }^{41}$ Mundt et al. ${ }^{14}$ demonstrated that AA women with locally advanced disease were less likely to receive intracavitary radiation therapy (ICRT) than white women $(13 \%$ vs $4 \% ; P=.07)$. This was attributed either to technical problems in placing the ICRT or to the greater prevalence of other comorbid health conditions in the AA women. In both the study by Mundt et al. and our study, receipt of radiation therapy was associated with better survival compared with no therapy.

Studies on histology and survival have demonstrated worsening survival for women who have nonsquamous histology compared with women who have squamous histology, ${ }^{16,23,34,38,42}$ consistent with our results. It has been postulated that this is because nonsquamous cancers are not detected as easily on Papanicolaou smears. It is noteworthy that, in the Cancer Prevention and Control Surveillance Program study, of 17,119 women evaluated, there were no statistically significant differences in 5-year relative survival rates between women with adenocarcinoma and women with SCC. However, when comparing survival rates for adenosquamous carcinoma with the rates for SCC, the 5-year relative survival was $54.9 \%$ for adenosquamous and $67.2 \%$ for SCC $(P=.05) .{ }^{38}$

The literature examining marital status and cervical cancer survival is scant. In the report by Murphy et al., ${ }^{19}>1000$ women from the South Thames Cancer Registry were classified as single, married, widowed, or divorced. That study indicated that, after adjustment for age, there were no significant differences in survival according to marital status. Our study indicated that being married tended to have a modest negative influence on survival, although we have no reasonable explanation for that finding.

The strengths of our study include the large population size, the long period of follow-up, and the use of SES on a census tract level. In articles that examined cervical cancer survival and SES, $6,7,14,16-236$ of 11 studies indicated that women with lower SES had poorer survival. $6,7,17,20-22$ Eggleston et al. ${ }^{7}$ reported on 5467 women with cervical cancer. In their 
study, an SES variable was defined by using measures of employment, income, education, and poverty at the zip code level. After adjusting for stage, lower SES was associated with poorer survival (HR, $1.9 ; 95 \%$ CI, $1.6-2.3 ; P<.001)$. In their report, AA race still was associated with poorer survival after adjusting for SES (HR, 1.3; 95\% CI, 1.1-1.5). In the study by Greenwald et al., ${ }^{18}$ race was associated independently with survival, but SES was not. In that study, SES was based on the percentage of high school graduates among individuals aged $\geq 25$ years in each zip code area. Race continued to predict mortality after adjusting for SES, although using education alone as a proxy for SES, especially in a large geographic area, may have not been an adequate method for estimating SES. In fact, SES has not been defined consistently in the literature, which may explain in part the variability in the reported results.

However, there are inherent problems in using the SEER registry for data collection. All data are collected from medical records and are only as complete or accurate as the original medical record. An evaluation of racial classification in the Detroit SEER registry revealed that AAs were 4 times more likely to be misclassified with regard to their race than whites, although the agreement between self-reported race and registry race was $99.7 \% .{ }^{43}$ Another potential problem is that we used overall survival as an outcome rather than cancer-specific survival, because the cause of death variable derived from death certificate information is prone to misclassification. ${ }^{44,45}$ In addition, differences in overall survival between AA women and white women may be related to a higher prevalence of comorbid conditions among AA women, data that are not collected in the SEER database. Some studies have evaluated the impact of comorbid conditions on cervical cancer survival, including the level of pretreatment hemoglobin during cancer-directed therapy to explain racial differences in cervical cancer survival ${ }^{14,15,46}$; however, further work needs to be done to evaluate the impact of other comorbid conditions on survival. There also are potential biologic differences in tumor aggressiveness and response to treatment between AA women and white women that should be evaluated further, because they may explain survival differences.

The current study adds to the existing literature on racial differences in cervical cancer using a population-based source of data. In addition, it offers a more refined method for studying racial differences in survival in the context of SES. Our results demonstrate that poor survival in AA women is explained at least in part by low SES as well as by other variables that have a potential impact on access to care. It is important for policy makers to improve access to early screening, early detection, and treatment opportunities to reduce and eventually, not only eliminating discrepancies in stage at presentation but also resulting in more equitable survival for all women who are diagnosed with cervical cancer. Furthermore, clinicians must remind women beyond their childbearing years of the importance of continuing to screen for cervical cancer.

\section{References}

1. Ries, LAG.; Harkins, D.; Krapcho, M., et al. SEER Cancer Statistics Review, 1975-2003. Bethesda, Md: National Cancer Institute; 2006.

2. American Cancer Society (2006). Cancer Facts and Figures. Atlanta, Ga: American Cancer Society; 2006.

3. Surveillance Epidemiology and End Results (SEER) Program. SEER*Stat Database. Bethesda, Md: National Cancer Institute, DCCPS, Surveillance Research Program, Cancer Statistics Branch; 2006. (www.seer.cancer.gov). Incidence-SEER 9 Regions. Public-Use, November 2005 submission (1973-2003) 
4. Leath CA III, Straughn JM Jr, Kirby TO, Huggins A, Partridge EE, Parham GP. Predictors of outcomes for women with cervical carcinoma. Gynecol Oncol. 2005; 99:432-436. [PubMed: 16137753]

5. Brooks SE, Baquet CR, Gardner JF, Moses G, Ghosh A. Cervical cancer-the impact of clinical presentation, health and race on survival. J Assoc Acad Minor Phys. 2000; 11:55-59. [PubMed: 11852650]

6. Morgan MA, Behbakht K, Benjamin I, Berlin M, King SA, Rubin SC. Racial differences in survival from gynecologic cancer. Obstet Gynecol. 1996; 88:914-918. [PubMed: 8942827]

7. Eggleston KS, Coker AL, Williams M, Tortolero-Luna G, Martin JB, Tortolero SR. Cervical cancer survival by socioeconomic status, race/ethnicity, and place of residence in Texas, 1995-2001. J Womens Health (Larchmont). 2006; 15:941-951.

8. Howell EA, Chen YT, Concato J. Differences in cervical cancer mortality among black and white women. Obstet Gynecol. 1999; 94:509-515. [PubMed: 10511350]

9. Chen F, Trapido EJ, Davis K. Differences in stage at presentation of breast and gynecologic cancers among whites, blacks, and Hispanics. Cancer. 1994; 73:2838-2842. [PubMed: 8194025]

10. del Carmen MG, Montz FJ, Bristow RE, Bovicelli A, Cornelison T, Trimble E. Ethnic differences in patterns of care of stage $1 \mathrm{~A}(1)$ and stage $1 \mathrm{~A}(2)$ cervical cancer: a SEER database study. Gynecol Oncol. 1999; 75:113-117. [PubMed: 10502436]

11. Mitchell JB, McCormack LA. Time trends in late-stage diagnosis of cervical cancer. Differences by race/ethnicity and income. Med Care. 1997; 35:1220-1224. [PubMed: 9413310]

12. Mandelblatt J, Andrews H, Kerner J, Zauber A, Burnett W. Determinants of late stage diagnosis of breast and cervical cancer: the impact of age, race, social class, and hospital type. Am J Public Health. 1991; 81:646-649. [PubMed: 2014871]

13. Jones WB, Shingleton HM, Russell A, et al. Patterns of care for invasive cervical cancer. Results of a national survey of 1984 and 1990. Cancer. 1995; 76(10 suppl):1934-1947. [PubMed: 8634985]

14. Mundt AJ, Connell PP, Campbell T, Hwang JH, Rotmensch J, Waggoner S. Race and clinical outcome in patients with carcinoma of the uterine cervix treated with radiation therapy. Gynecol Oncol. 1998; 71:151-158. [PubMed: 9826453]

15. Katz A, Eifel PJ, Moughan J, Owen JB, Mahon I, Hanks GE. Socioeconomic characteristics of patients with squamous cell carcinoma of the uterine cervix treated with radiotherapy in the 1992 to 1994 Patterns of Care study. Int J Radiat Oncol Biol Phys. 2000; 47:443-450. [PubMed: 10802372]

16. Coker AL, Du XL, Fang S, Eggleston KS. Socioeconomic status and cervical cancer survival among older women: findings from the SEER-Medicare linked data cohorts. Gynecol Oncol. 2006; 102:278-284. [PubMed: 16434087]

17. Bradley CJ, Given CW, Roberts C. Health care disparities and cervical cancer. Am J Public Health. 2004; 94:2098-2103. [PubMed: 15569960]

18. Greenwald HP, Polissar NL, Dayal HH. Race, socioeconomic status and survival in three female cancers. Ethn Health. 1996; 1:65-75. [PubMed: 9395549]

19. Murphy M, Goldblatt P, Thornton-Jones H, Silcocks P. Survival among women with cancer of the uterine cervix: influence of marital status and social class. J Epidemiol Commun Health. 1990; 44:293-296.

20. Samelson EJ, Speers MA, Ferguson R, Bennett C. Racial differences in cervical cancer mortality in Chicago. Am J Public Health. 1994; 84:1007-1009. [PubMed: 8203665]

21. Shelton D, Paturzo D, Flannery J, Gregorio D. Race, stage of disease, and survival with cervical cancer. Ethn Dis. 1992; 2:47-54. [PubMed: 1458215]

22. Singh GK, Miller BA, Hankey BF, Edwards BK. Persistent area socioeconomic disparities in U.S. incidence of cervical cancer, mortality, stage, and survival, 1975-2000. Cancer. 2004; 101:10511057. [PubMed: 15329915]

23. Farley JH, Hines JF, Taylor RR, et al. Equal care ensures equal survival for African-American women with cervical carcinoma. Cancer. 2001; 91:869-873. [PubMed: 11241257]

24. Krieger N, Chen JT, Waterman PD, Soobader MJ, Subramanian SV, Carson R. Geocoding and monitoring of US socioeconomic inequalities in mortality and cancer incidence: does the choice of 
area-based measure and geographic level matter? The Public Health Disparities Geocoding Project. Am J Epidemiol. 2002; 156:471-482. [PubMed: 12196317]

25. Krieger N, Waterman P, Chen JT, Soobader MJ, Subramanian SV, Carson R. Zip code caveat: bias due to spatiotemporal mismatches between zip codes and US Census-defined geographic areasthe Public Health Disparities Geocoding Project. Am J Public Health. 2002; 92:1100-1102. [PubMed: 12084688]

26. Krieger N, Chen JT, Waterman PD, Rehkopf DH, Subramanian SV. Race/ethnicity, gender, and monitoring socioeconomic gradients in health: a comparison of area-based socioeconomic measures-the Public Health Disparities Geocoding Project. Am J Public Health. 2003; 93:16551671. [PubMed: 14534218]

27. Krieger N, Quesenberry C Jr, Peng T, et al. Social class, race/ethnicity, and incidence of breast, cervix, colon, lung, and prostate cancer among Asian, black, Hispanic, and white residents of the San Francisco Bay Area, 1988-92 (United States). Cancer Causes Control. 1999; 10:525-537. [PubMed: 10616822]

28. World Health Organization. International Classification of Diseases for Oncology. 2. Geneva, Switzerland: World Health Organization; 1990.

29. Weir HK, Thun MJ, Hankey BF, et al. Annual report to the nation on the status of cancer, 19752000, featuring the uses of surveillance data for cancer prevention and control. J Natl Cancer Inst. 2003; 95:1276-1299. [PubMed: 12953083]

30. Devita, VT. Cancer: Principles and Practice of Oncology. Philadelphia, Pa: Lippincott Williams \& Wilkins; 2007.

31. United States Bureau of the Census. Census of Population and Housing Summary Tape File 3, Technical Documentation, 1991. Washington DC: US Census Bureau; 1990.

32. Patel DA, Barnholtz-Sloan JS, Patel MK, Malone JM Jr, Chuba PJ, Schwartz K. A populationbased study of racial and ethnic differences in survival among women with invasive cervical cancer: analysis of Surveillance, Epidemiology, and End Results data. Gynecol Oncol. 2005; 97:550-558. [PubMed: 15863159]

33. Grigsby PW, Hall-Daniels L, Baker S, Perez CA. Comparison of clinical outcome in black and white women treated with radiotherapy for cervical carcinoma. Gynecol Oncol. 2000; 79:357-361. [PubMed: 11104605]

34. Thoms WW, Unger ER, Johnson PR, et al. Cervical cancer survival in a high risk urban population. Cancer. 1995; 76:2518-2523. [PubMed: 8625079]

35. Ragland KE, Selvin S, Merrill DW. Black-white differences in stage-specific cancer survival: analysis of seven selected sites. Am J Epidemiol. 1991; 133:672-682. [PubMed: 2018022]

36. Brewster WR, DiSaia PJ, Monk BJ, Ziogas A, Yamada SD, Anton-Culver H. Young age as a prognostic factor in cervical cancer: results of a population-based study. Am J Obstet Gynecol. 1999; 180(6 pt 1):1464-1467. [PubMed: 10368490]

37. Bolli JA, Maners A. Age as a prognostic factor in cancer of the cervix: the UAMS experience. J Ark Med Soc. 1992; 89:79-83. [PubMed: 1629111]

38. Kosary CL. FIGO stage, histology, histologic grade, age and race as prognostic factors in determining survival for cancers of the female gynecological system: an analysis of 1973-1987 SEER cases of cancers of the endometrium, cervix, ovary, vulva, and vagina. Semin Surg Oncol. 1994; 10:31-46. [PubMed: 8115784]

39. Brun JL, Stoven-Camou D, Trouette R, Lopez M, Chene G, Hocke C. Survival and prognosis of women with invasive cervical cancer according to age. Gynecol Oncol. 2003; 91:395-401. [PubMed: 14599872]

40. Meanwell CA, Kelly KA, Wilson S, et al. Young age as a prognostic factor in cervical cancer: analysis of population based data from 10,022 cases. Br Med J (Clin Res Ed). 1988; 296:386-391.

41. Morrow, CP.; Curtin, JP. Synopsis of gynecologic oncology. New York: Churchill Livingstone; 1998.

42. McCusker ME, Cote TR, Clegg LX, Tavassoli FJ. Endocrine tumors of the uterine cervix: incidence, demographics, and survival with comparison to squamous cell carcinoma. Gynecol Oncol. 2003; 88:333-339. [PubMed: 12648583] 
43. Patel DA, Knowles A, Schwartz AG, Schwartz K. Evaluation of African-American and white racial classification in a Surveillance, Epidemiology, and End Results cancer registry. Ethn Dis. 2005; 15:713-719. [PubMed: 16259498]

44. Chow WH, Devesa SS. Underreporting and misclassification of urinary tract cancer cases on death certificates. Epidemiology. 1996; 7:517-520. [PubMed: 8862984]

45. Weinstock MA, Reynes JF. Validation of cause-of-death certification for outpatient cancers: the contrasting cases of melanoma and mycosis fungoides. Am J Epidemiol. 1998; 148:1184-1186. [PubMed: 9867264]

46. Winter WE III, Maxwell GL, Tian C, et al. Association of hemoglobin level with survival in cervical carcinoma patients treated with concurrent cisplatin and radiotherapy: a Gynecologic Oncology Group study. Gynecol Oncol. 2004; 94:495-501. [PubMed: 15297194] 


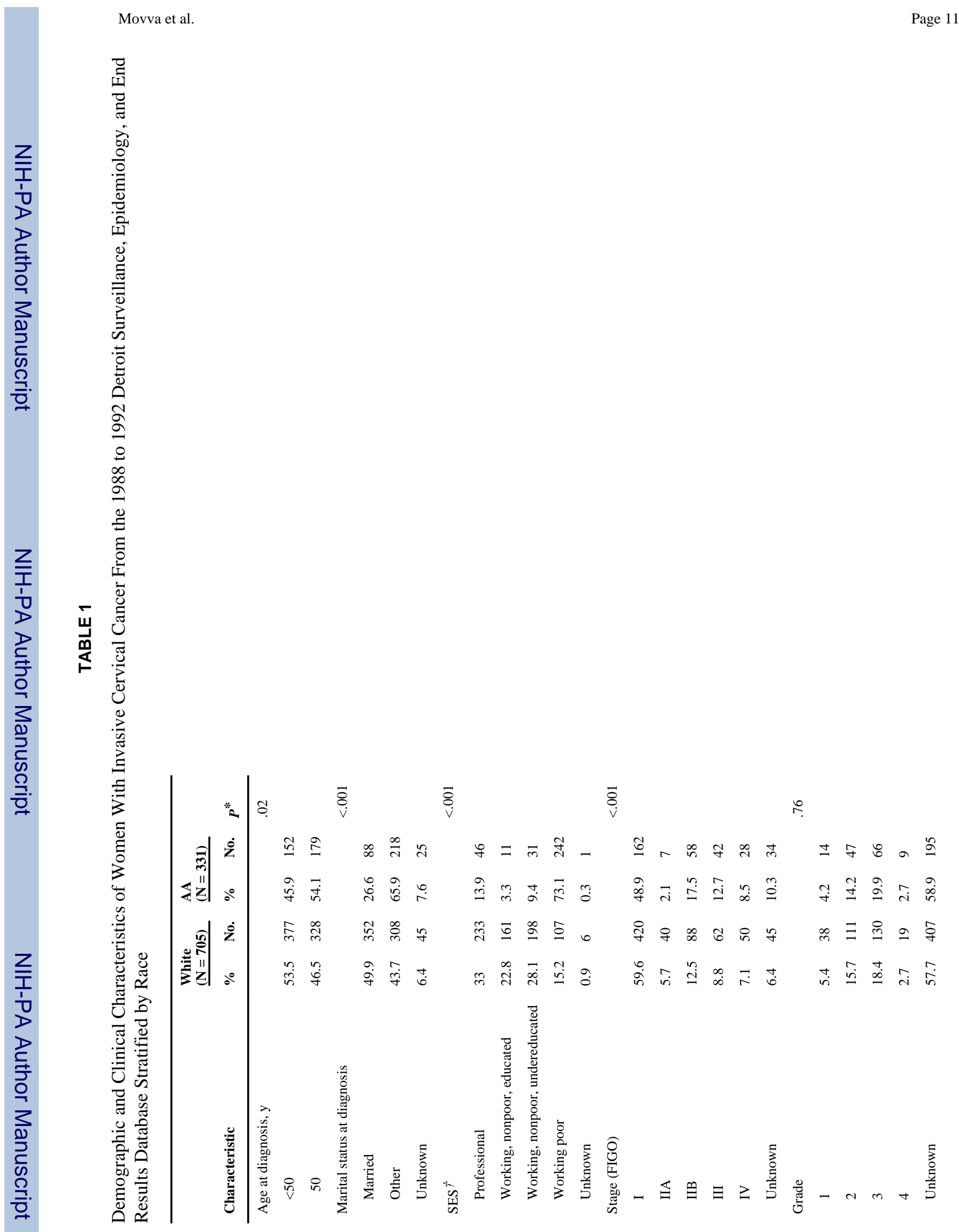

Cancer. Author manuscript; available in PMC 2013 October 18. 


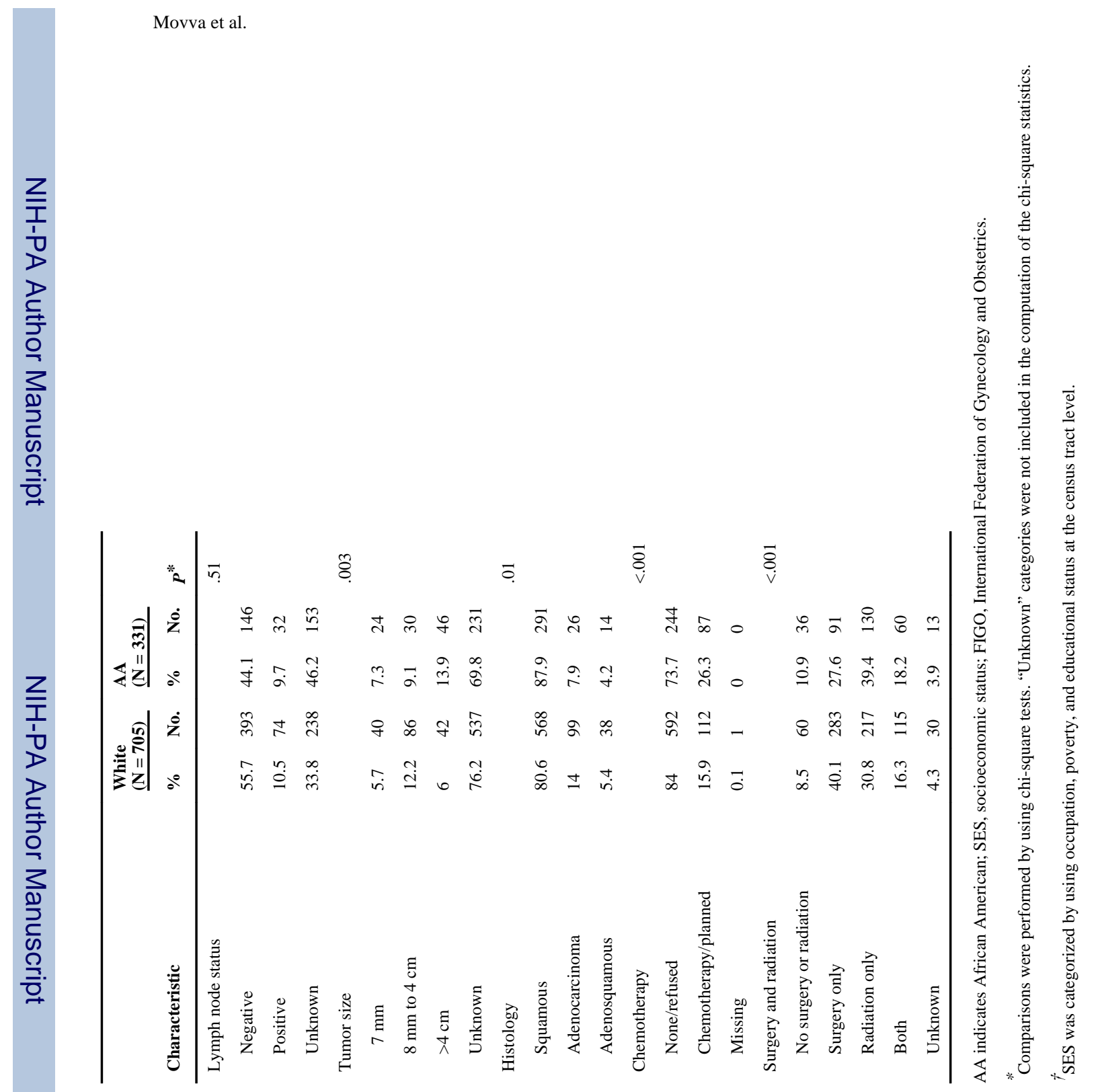

Page 12

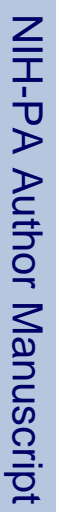

Cancer. Author manuscript; available in PMC 2013 October 18. 
TABLE 2

Multivariate Predictors of Overall Survival Using Cox Proportional Hazards Modeling in Women From the 1988 to 1992 Detroit Surveillance, Epidemiology, and End Results Database $(\mathrm{N}=862)$

\begin{tabular}{|c|c|c|c|c|}
\hline Variable/Comparison* & Time since diagnosis, $y$ & HR & $95 \% \mathrm{CI}$ & $P$ \\
\hline \multicolumn{5}{|l|}{ Race } \\
\hline Black vs white & Any & 1.12 & $0.89-1.42$ & .33 \\
\hline \multicolumn{5}{|l|}{ Age. y } \\
\hline 250 vs $<50$ & Any & 2.28 & $1.84-2.83$ & $<.001$ \\
\hline \multicolumn{5}{|l|}{ Marital status at diagnosis } \\
\hline Married vs other & Any & 1.23 & $1.01-1.50$ & .04 \\
\hline \multicolumn{5}{|l|}{$\mathrm{SES}^{\dagger}$} \\
\hline WP vs P & Any & 1.30 & $1.00-1.69$ & .05 \\
\hline WNP-UE vs P & Any & 1.12 & $0.85-1.47$ & .43 \\
\hline WNP-E vs P & Any & 0.99 & $0.72-1.35$ & .93 \\
\hline \multicolumn{5}{|l|}{ Histology } \\
\hline Adenocarcinoma vs squamous & Any & 1.89 & $1.41-2.54$ & $<.001$ \\
\hline Adenosquamous vs squamous & Any & 2.34 & $1.62-3.37$ & $<.001$ \\
\hline \multicolumn{5}{|l|}{ Stage } \\
\hline \multirow[t]{3}{*}{ II vs I } & 2 & 1.96 & $1.45-2.66$ & $<.001$ \\
\hline & 4 & 1.65 & $1.26-2.17$ & $<.001$ \\
\hline & 6 & 1.39 & $1.05-1.85$ & .02 \\
\hline \multirow[t]{3}{*}{ III vs I } & 2 & 3.50 & $2.44-5.01$ & $<.001$ \\
\hline & 4 & 2.69 & $1.90-3.80$ & $<.001$ \\
\hline & 6 & 2.07 & $1.40-3.06$ & $<.001$ \\
\hline \multirow[t]{3}{*}{ IV vs I } & 2 & 9.04 & $6.10-13.40$ & $<.001$ \\
\hline & 4 & 5.85 & $3.46-9.89$ & $<.001$ \\
\hline & 6 & 3.79 & $1.78-8.03$ & $<.001$ \\
\hline \multicolumn{5}{|l|}{ Chemotherapy } \\
\hline Received vs none & Any & 1.10 & $0.87-1.40$ & .43 \\
\hline \multicolumn{5}{|l|}{ Surgery and radiation } \\
\hline Surgery only vs neither & Any & 0.15 & $0.10-0.23$ & $<.001$ \\
\hline Radiation only vs neither & Any & 0.50 & $0.33-0.76$ & $<.001$ \\
\hline Both vs neither & Any & 0.38 & $0.25-0.58$ & $<.001$ \\
\hline
\end{tabular}

HR indicates hazard ratio; CI, confidence interval; SES, socioeconomic status; WP, working poor; P, professional; WNP-UE, working, nonpoor, undereducated; WNP-E, working, nonpoor, educated.

The model included all of the variables listed in the table.

${ }^{\dagger}$ SES was categorized by using occupation, poverty, and educational status at the census tract level. 